\title{
STUDY OF A RELATIONSHIP BETWEEN THE CRITERIA FOR SELECTION OF THE TRANSPORT TECHNOLOGY FOR THE PASSENGERS CARRIAGE USING THE DEMATEL METHOD
}

This study defines criteria and sub-criteria for evaluation of the transport technology for carriage of passengers by railway and road transport. The main criteria are divided into four groups: business, environmental, social and technological, named BEST analysis. Twenty-four sub-criteria have been examined. The method of multi-criteria analysis Decision Making Trial and Evaluation Laboratory (DEMATEL) has been applied to analyse importance and the relations between the criteria. Results show that e criteria of the great importance are business group (29.47\%) and technological group (27.49\%). The sub-criteria: transport costs for fuel (7.83\%); ticket price (8.29\%); time travel (6.99\%); directness (6.4\%) and direct operating costs (6.30\%) are the most important. The defined criteria and subcriteria can be applied for evaluation, comparison and selection the transportation variant.

Keywords: DEMATEL method, transport technology, passenger, multi-criteria analysis

\section{Introduction}

The choice of criteria for assessing the technology for carriage of passengers is an important task in organization of transport. The transport plan of passengers depends on various criteria that on the one hand, are important for transport operators, and on the other hand are significant for passengers. The main factors for the quality of the transport service are speed, direct journey, frequency, security and ticket price. The fuel consumption, operating costs, taxes are major factors for the transport operator.

Carriage of passengers by the bus transport is performed mostly by private companies that have a different position in the transport services market. The railway transport is in the most cases carried out by public operators or public and private transport companies.

The different criteria have different weights when choosing a transport plan, as well as different interactions. It is therefore necessary to examine the problem of assessing the mutual influence between the criteria.

The problem of choosing criteria for evaluation and selection of transport has been a subject of research by various authors.

In [1] authors determined convenience and comfort as the main criteria for measurement of the bus transit services quality. The main group convenience contains the sub-criteria: span of service, frequency, capacity, accessibility, network coverage. The sub-criteria comfort contains the sub-criteria for the main group criteria: vehicle occupancy rate, speed, air-conditioned vehicle rate, route directness. The Analytic hierarchy process (AHP) method has been applied to determine weights of the main criteria and sub-criteria. It was found that the frequency, capacity and route directness are the most important criteria from the passengers' point of view.

In [2] the Principal Component Analysis method, Quality Function Deployment and an interval-valued intuitionistic fuzzy approach have been used to analyse the customer satisfaction criteria of public transport. The criteria that were studied are frequency, convenience, information, travel time, driver behaviour, cleanliness and ergonomics, safety and security, emission reduction. The methodology is applied for Istanbul. It was found that the most important areas for the bus users according to the questionnaire research are frequency and time; the safety and security, and emission reduction are the most important factors according to the decision maker's weights.

The following travel purposes are examined in [3] business trips, holiday and leisure trips. The distance and seventeen criteria including price, travel time, reliability, flexibility, simplicity, safety, safety (crime), sustainability, infrastructure, comfort, staff, pastime, image, luggage, pet policy, social contacts, accessibility, have been studied as the key factors of a modal choice, as well. It was found that the most significant determinants for all the trip categories are price, travel time/speed, convenience/ comfort, reliability and carriage of luggage.

The goal programming methodology integrated with the AHP method is applied in [4] for performance optimization of public transport undertakings. Twelve decision variables are identified, taking into account both user and operator perceptions: controllable costs, no controllable costs, taxes, 
staff per bus ratio (fleet operated), safety, accessibility, regularity, load factor, fleet utilization, percentage of effective kilometers, journey speed and percentage of cancelled kilometers to scheduled kilometers. It was found that the operator costs and staff per schedule are the most important variables for the operator, whereas among the user perceptions, safety of travel has the highest weighting.

Passenger satisfaction, as the quality criteria of public transport has been analysed in [5]. The time accessibility criteria, which include accessibility of stops, waiting for a connection and transferability in the public transport network, are considered as the most significant criteria that influence a passenger's decision to utilize public transport options. In [6] the authors studied the bus passenger comfort perception based on passenger load factor and in-vehicle time. The quality of intercity road transportation of passengers, according to the customers' perspective, is studied in [7]. The main factors that have influence on quality of service are attendance (degree of courtesy of staff, fast and organized queues, staff appearance and ease of purchasing tickets), vehicle (vehicle condition, bathroom existence, air conditioning existence, vehicle cleanliness and accessibility to disabled people), route (departure time as scheduled, variety of departure times, appropriate travel time, quantity of stops along the route), passengers security, differential services, ticket fare.

In [8] are considered the seventeen criteria in 4-dimensions (economical; environmental; social; risk and security) are considered to assess five simulation scenarios of the Bus Rapid System service. The grey SWARA method is applied to determine the weights of criteria. The alternatives were assessed by using the grey COPRAS method. In [9] the following criteria for evaluation of the $\mathrm{CO}_{2}$ emission strategies have been determined: air pollution, traffic congestion, investment costs and natural environment. The authors examined three strategies: reduce the $\mathrm{CO}_{2}$ emissions per kilometer, avoid using personal car, replace Fossil Fuel. The AHP method has been used to assess the weights of criteria and to prioritize the strategies.

The different transportation solution has been assessed by criteria average travel time, traffic safety, investment costs, investment profitability, environmental friendliness [10]. Computational experiments have been carried out with use of ELECTRE III and AHP methods.

In [11] the authors defined the criteria that allow evaluating the transportation activity in an agribusiness industry: transportation costs, delivery time, fleet modernity, transportation reliability, transportation quality, safety, environmental friendliness, fleet utilization. It was found that the most important criterion with the highest value of weights is the transportation costs criterion. The next places are held by criterion delivery time and transportation quality. In [12] the speed, reliability, capacity, costs and safety factors are used to assess three timetables for the train services on the Iran rail network. In [13] the indicators safety, rapidity, time and comfort are applied to analyse the qualitative factors, which influences the operation efficiency of the transport enterprises in the highway passenger. In [14-15] the criteria direct operating costs, average speed, availability of service with direct transport, reliability, transport satisfaction, average number of train stops, average distance travelled and the transport capacity have been defined to evaluate the scheme of transportation of intercity trains.

The cluster analysis is used in [16] to identify advantages and disadvantages of five modes of transport. The following criteria have been investigated: comfort, time, costs, accessibility and safety. It was found that the comfort is the most important one.

It can be summed up that the most important criteria, which affect the transport process are the economical; environmental; ticket fare, travel time, speed, frequency, capacity, route directness, security, reliability.

The multi-criteria analysis is an appropriate method for assessment of criteria and determination of their weights. Most methods only define the weights without investigation of the mutual influence between the criteria. Some of multicriteria methods as Decision Making Trial and Evaluation Laboratory (DEMATEL) method and Analytic Network Process (ANP) allow conducting an analysis of criteria. The DEMATEL method permits to draw up the cause-effect model, which represents the relationships between criteria.

This paper aims to propose an approach for examining the criteria for choice of the transport technology for the passengers carriage, their impact and relationship by taking into account the transportation process. This study applies the method of multi-criteria analysis Decision Making Trial and Evaluation Laboratory (DEMATEL) method to study the criteria and their interdependencies to establish the relationship between the causes and effects of criteria into a structural model.

\section{Methodology}

The methodology of research includes the following steps:

Step 1: Defining the criteria for choice of transport technology for the carriage of passengers.

Step 2: Application of the DEMATEL method for assessment of a relationship between the criteria

\subsection{Defining the criteria for assessment of the transport technology for passenger transportation}

This study includes BEST multi-criteria analysis (Business, Environmental, Social, and Technological) by determining the main criteria and sub-criteria for assessment of the transport technologies for the carriage of passengers. The main criteria are as follows:

- B - Business criteria. These include economic criteria for realisation of the transport process.

- E - Environmental criteria. These criteria include assessment of environmental pollutants from transport. 
- S - Social criteria. They are related to the passengers' requirements.

- $\mathrm{T}$ - Technological criteria. They are related to realization of the transportation.

The sub-criteria for the main group Business criteria (B) are B1 - Transport costs for fuel (electric energy); B2 Ticket price.; B3 - Direct operating costs; B4 - Infrastructure charges; B5 - Company position in the market.

The sub-criteria for the main group Environmental criteria (E) are $\mathrm{E} 1$ - Carbon dioxide $\left(\mathrm{CO}_{2}\right), \mathrm{g} /($ pass.km); E2 - Carbon monoxide (CO), g/(pass.km); E3 - Nitrogen oxides (NOx), g/(pass.km); E4 - Non-methane hydrocarbons (NC), g/(pass.km); E5 - Particulate matter (PM), g/(pass.km).

The sub-criteria for the main group Social criteria (S) are S1 - Comfort; S2 - Security; S3 - Reliability; S4 - Stability; S5 - Punctuality; S6 - Cleanliness, ergonomics; S7 - Security and comfort in the place of time-off.

The sub-criteria for the main group Technological criteria (T) are T1 - Time travel; T2 - Frequency of shipments; T3 - Directness; T4 - Number of stops; T5 - Service period; T6 - Vehicle occupancy rate; T7 - State of infrastructure.

The sub-criteria Company position in the market (B5), Social group sub-criteria: S1-S7, Directness (T3) and State of infrastructure (T7) are qualitative and others sub-criteria are quantitative. The qualitative sub-criteria can have values for example 0 or $1 ; 1$ - if the answer is yes; 0 otherwise. The criterion Company position in the market (B5) could be determined for example as a good (value 1) or bad (value 0 ) according to the demand for transportation from the passenger.

\subsection{DEMATEL Method}

This study applies the DEMATEL method to evaluate the criteria and their interdependencies. The procedure of DEMATEL method is summarized as follows [17]:

- Step 1: Formation of experts 'perception matrixes. Each expert evaluates the direct influence between any two criteria by using an integer score as follows: 0 - no influence; 1 - low influence; 2 - medium influence; 3 - high influence; 4 - very high influence. For each established a matrix $X^{k}=\left[x_{i j}^{k}\right]_{n x n}$ was established, where $k=1, \ldots, H$ is the number of experts; $n$ is the number of criteria; $x_{i j}^{k}$ indicates the degree to which the expert assesses factor $i$ affects factor $j$. For $i=j$, the diagonal elements of each expert answer matrix are set to zero.

- Step 2: Determination of the average answer matrix $A=\left[a_{i j}\right]_{n x n}$. The elements of the average perception matrix $A$ are calculated as follows:

$a_{i j}=\frac{1}{H} \sum_{k=1}^{H} x_{i j}^{k}$.

- Step 3: Determination of the average normalized perception matrix $D=\left[d_{i j}\right] n x n$

$D=A / S$ where: $A$ is the average answer matrix; $S$ is the major value of the sum of each column $j$ of the matrix $A$ and the major value of the sum of each row $i$ of the matrix $A$.

The values of each element in matrix $D$ are between 0 and 1 .

- Step 4: Determination of the total relation matrix $T=\left[t_{i j}\right]_{n \times n}$

$T=D(I-D)^{-1}$,

where: $I$ is an $n x n$ identity matrix.

- Step 5: Determination of the both direct and indirect effects between criteria.

The sum of the columns and the sum of the rows of the matrix $T$ are determined.

The vector R represents the sums of rows of the $T$ matrix. The vector $\mathrm{C}$ represents the sum of columns of the $T$ matrix.

$R=\left[r_{i}\right]_{n x 1}=\left[\sum_{j=1}^{n} t_{i j}\right]_{n x 1}$,

$C=\left[c_{i}\right]_{1 x n}^{\prime}=\left[\sum_{i=1}^{n} t_{i j}\right]_{1 x n}$,

where: $r_{i}$ is the sum of the $i$-th row in matrix $T ; c_{j}$ is the sum of the $j$-th column in matrix $T$; ' is the symbol that denotes the transposed matrix.

Both the direct and indirect effects by the $i$-th criterion on the other criteria are presented by the elements of vector; the both direct and indirect effects by criterion $j$ from the other criteria are shown by the elements of vector $C$.

The sum of columns and rows $(\mathrm{R}+\mathrm{C})$ called "Prominence" means that all the criteria are relatively important. According to the difference (R-C) named "Relation" the criteria are divided into a cause and effect group depending upon the positive and negative values of all the elements in the $(\mathrm{R}-\mathrm{C})$ column.

Step 6: For each criterion the normalized degree of influence is determined as follows:

$e_{i}=\frac{r_{i}+c_{i}}{\sum_{i=1}^{n}\left(r_{i}+c_{i}\right)} \cdot 100 \%$,

where: $r_{i}, c_{i}$ are the elements of vector $\mathrm{R}$ and vector $\mathrm{C}$.

The degree of influence presents also the weights of criteria.

- Step 7: Determination of the threshold value. It serves to calculate the relationships between criteria in the considered system. Elements that are smaller or equal to the threshold value $v$, are set to zero. Elements that are larger than the threshold value $v$, retain their value.

The threshold value $v$ is determined as an average value of elements of matrix $T$ [18]:

$v=\frac{\sum_{i=1}^{n} \sum_{j=1}^{n}\left[t_{i j}\right]}{N}$,

where: $N$ - the total number of elements in the matrix $T$.

- $\quad$ Step 8. Drawing a relationship diagram.

The relationship diagram is drawn by coordinate sets by $\left(r_{i}+c_{i}\right),\left(r_{i}-c_{i}\right)$ to visualize the complex interrelationship. It gives an information on which are the most important factors and how they influence the affected factors. The diagram includes the factors $t_{i j}$ that are greater than threshold 
Table 1 Average Matrix A for the Main group criteria

\begin{tabular}{|c|c|c|c|c|c|}
\hline Criteria & B & $\mathrm{E}$ & $\mathrm{S}$ & $\mathrm{T}$ & Total \\
\hline B & 0.0 & 1.2 & 1.5 & 2.0 & 4.7 \\
\hline $\mathrm{E}$ & 1.1 & 0.0 & 0.8 & 0.4 & 2.3 \\
\hline $\mathrm{S}$ & 1.3 & 1.0 & 0.0 & 1.1 & 3.4 \\
\hline $\mathrm{T}$ & 2.2 & 0.8 & 1.7 & 0.0 & 4.7 \\
\hline Total & 4.6 & 3.0 & 4.0 & 3.5 & - \\
\hline
\end{tabular}

Table 2 Average normalized perception matrix $D$ for the Main group criteria

\begin{tabular}{cccccc}
\hline Criteria & B & E & S & T \\
B & 0.00 & 0.26 & 0.32 & 0.17 & 0.09 \\
E & 0.23 & 0.00 & 0.00 & 0.23 \\
S & 0.28 & 0.21 & 0.36 & 0.00 \\
T & 0.47 & 0.17 & 0 & \\
\hline
\end{tabular}

Table 3 Total Relation Matrix T. Direct and indirect influence for the Main group criteria

\begin{tabular}{cccccccccccc}
\hline Criteria & $\mathrm{B}$ & $\mathrm{E}$ & $\mathrm{S}$ & $\mathrm{T}$ & $\mathrm{R}$ & $\mathrm{C}$ & $\mathrm{R}+\mathrm{C}$ & $\mathrm{R}-\mathrm{C}$ & $\mathrm{e}(\%)$ & Rank & Impact \\
\hline $\mathrm{B}$ & $1.356^{*}$ & $1.161^{*}$ & $1.472^{*}$ & $1.446^{*}$ & 5.435 & 5.216 & 10.651 & 0.219 & 29.47 & 1 & Cause \\
$\mathrm{E}$ & 0.908 & 0.523 & 0.804 & 0.704 & 2.940 & 3.725 & 6.665 & -0.786 & 18.44 & 4 & Effect \\
$\mathrm{S}$ & $1.244^{*}$ & 0.910 & 0.935 & 1.060 & 4.150 & 4.738 & 8.888 & -0.588 & 24.59 & 3 & Effect \\
$\mathrm{T}$ & $1.707^{*}$ & $1.132^{*}$ & $1.526^{*}$ & $1.180^{*}$ & 5.545 & 4.390 & 9.935 & 1.155 & 27.49 & 2 \\
\hline \multicolumn{7}{c}{ Threshold value is 1.129. With * are shown the elements greater than or equal to the threshold value. } \\
\hline \multicolumn{8}{c}{}
\end{tabular}

value $v$. The coordinate is speared into four parts [19]: $\left(r_{i}-c_{i}\right)$ is positive and $\left(r_{i}+c_{i}\right)$ is large. This indicates that the criteria are causes, which are also key factors for solving problems; $\left(r_{i}-c_{i}\right)$ is positive and $\left(r_{i}+c_{i}\right)$ is small. This indicates that the criteria are independent and can influence only a few other factors; $\left(r_{i}-c_{i}\right)$ is negative and $\left(r_{i}+c_{i}\right)$ is large. This indicates that the criteria are the core problems that must be solved; however these are the effect-type criteria, which are of indirect impact; $\left(r_{i}-c_{i}\right)$ is negative and $\left(r_{i}+c_{i}\right)$ is small. This indicates that the factors are independent and can be influenced only by a few others attributes.

Therefore, the decision makers can visually study the complex causal relationships between criteria and also take decision about investigated system.

\section{Results and discussion}

The main group criteria and all 24 sub-criteria were evaluated by 7 experts, who are specialists with long experience in transport by academia (3 experts) and specialists by railway and automotive administration (4 experts). Each expert has given assessment according to scale 0-4 of the pair-wise comparisons between criteria.

Table 1 presents the average answer matrix for the main group criteria. The end row represents the sum of the columns; the end column represents the sum of the rows of the average answer matrix. Table 2 shows the average normalized perception matrix. Values of elements of this matrix are determined according to Equation (2); the value $\mathrm{S}=4.7$.
Table 3 presents the total relation matrix $T$ and values of direct and indirect influence for main group criteria. The threshold value determined by Equation (7) is 1.129. The elements that are larger than the threshold value are marked. The end column of the table indicates the weights of criteria, rank of the criteria and their impact.

The column $(\mathrm{R}+\mathrm{C})$ indicates the importance of the criteria. The column (R-C) serves to separate the criteria into cause group and effect group. The cause group factors have a direct impact on the overall system. The effect group factors are influenced by other factors.

Results in Table 3 show:

- The Business criteria (B) have the highest degree of importance (weight 29.47\%).

- The prioritization is $\mathrm{B}>\mathrm{T}>\mathrm{S}>\mathrm{E}$.

- The Business criteria (B) and Technological criteria (T) have close weights.

- The Business criteria (B) and Technological criteria (T) have positive values of the (R-C) named "Relation". Therefore, they are in the cause group.

- The Environmental criteria (E) and Social criteria (S) have negative values of the (R-C). Therefore, they are in the effect group.

Figure 1 presents the cause and effect diagram of the main group criteria. The parts of the diagram are formed according to the main of $(\mathrm{R}+\mathrm{C})$; it is 5.325 (by Table 3 , value 10.65). The dashed line in the figure shows the division of the four parts. The arrows in the figure present the relationships between criteria according to the threshold value and the marked elements in the total relation matrix presented in Table 3. 


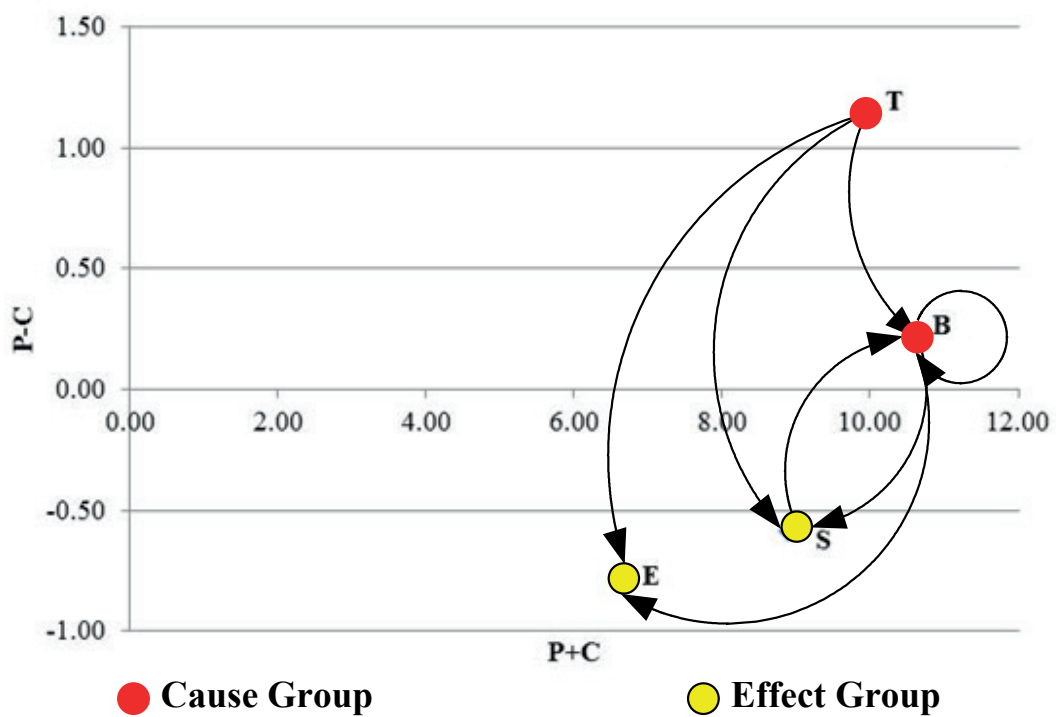

Figure 1 The cause and effect diagram of main criteria. Threshold value $v=1.129$

Table 4 Sub-criteria. The Average Matrix A

\begin{tabular}{|c|c|c|c|c|c|c|c|c|c|c|c|c|c|c|c|c|c|c|c|c|c|c|c|c|}
\hline & B1 & 32 & B3 & B4 & B5 & E1 & E2 & E3 & $\mathrm{E} 4$ & E5 & $\mathrm{S} 1$ & $\mathrm{~S} 2$ & S3 & $\mathrm{S} 4$ & S5 & $\mathrm{S} 6$ & S7 & $\mathrm{T} 1$ & $\mathrm{~T} 2$ & T3 & $\mathrm{T} 4$ & $\mathrm{~T} 5$ & $\mathrm{~T} 6$ & $\mathrm{~T} 7$ \\
\hline B1 & 0.0 & 15 & 17 & 07 & 1.0 & 0.8 & 0.8 & 08 & 0.8 & 0.8 & 1.0 & 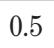 & 0.5 & 5 & 08 & 0.5 & 0 & 0.5 & 0.5 & 0.5 & 0.5 & 0.5 & 1.0 & 0.5 \\
\hline $\mathrm{B}$ & 1.3 & 0.0 & 1.0 & 1.4 & 0.5 & 0.2 & 0.2 & 0.2 & 0.2 & 0.2 & 1 & 5 & ( & 0.5 & 0.5 & 8 & 0.0 & 5 & 0 & 5 & 4 & 3 & .0 & 1 \\
\hline B3 & 1.0 & 2.0 & 0.0 & 0.0 & 0.0 & 0.1 & 0.1 & 0.1 & 0.1 & 0.1 & 0.5 & 2 & 0.2 & 0.0 & 0.0 & 0.3 & .0 & 1.5 & 0.2 & 1.0 & 0.6 & .2 & 0.3 & 0.1 \\
\hline B4 & 0.1 & 1.0 & 1.0 & 0.0 & 0 & 0.5 & 0. & 0.5 & 0.5 & 5 & 0.0 & 3 & 0.0 & 0.0 & 0.0 & 0.0 & 0.0 & 0.0 & 0.0 & 0.0 & 0.0 & 0.1 & 0.3 & 0.2 \\
\hline B5 & 0.5 & 0.5 & 0.4 & 04 & 0.0 & 0.4 & 0.4 & 0.4 & 0.4 & 0.4 & 0.7 & 0.5 & 0.5 & 0. & 0.4 & 0.4 & 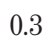 & 0.3 & 0.5 & 0.5 & 0.8 & .5 & 0.5 & 0.0 \\
\hline $\mathrm{E}$ & 0.8 & 0.3 & 0.3 & 0.0 & 0.5 & 0.0 & 0.0 & .0 & 0.0 & 0.0 & 0. & 0.1 & 0.3 & 0.3 & 0.0 & 0.0 & 0.0 & 0.0 & .0 & 0 & .3 & 0 & 0.0 & 0.0 \\
\hline E2 & 0.8 & 0.3 & 0.3 & 0.0 & 0.5 & 0.0 & 0.0 & 0.0 & 0.0 & 0.0 & 0.3 & 0.1 & 0.3 & 0.3 & 0.0 & 0.0 & 0.0 & 0.0 & 0.0 & 0.0 & 0.3 & 0.0 & 0.0 & 0.0 \\
\hline E3 & 0.8 & 0. & 0.3 & 0.0 & 0 & 0.0 & 0.0 & 0.0 & 0. & 0 & 0.3 & 1 & 0.3 & 03 & 0.0 & 0.0 & 0 & 0.0 & 0 & 0.0 & 03 & 0.0 & 0.0 & 0.0 \\
\hline $\mathrm{E} 4$ & 0.8 & 0 . & 0.3 & 0.0 & 0.5 & 0.0 & 0.0 & 0.0 & 0. & 0 & 0.3 & 0.1 & 0.3 & 0.3 & 0.0 & 0.0 & 0.0 & 0.0 & 0.0 & 0.0 & 0.3 & 0.0 & 0.0 & 0.0 \\
\hline $\mathrm{E}$ & 0.8 & 0.3 & 0.3 & 0.0 & 0.5 & 0.0 & 0.0 & 0.0 & 0.0 & 0.0 & 0.3 & 0.1 & 0.3 & 0.3 & 0.0 & 0.0 & 0.0 & 0.0 & 0.0 & 0.0 & 0.3 & 0.0 & 0.0 & 0.0 \\
\hline S1 & 0.5 & 0.6 & 0.6 & 0.0 & 0. & 0.2 & 0 & 0.2 & 0 & 0.2 & 0.0 & 0.5 & 0.8 & 0.8 & 0.5 & 0.8 & 0.8 & 0.1 & 0.4 & 0.5 & 0.8 & 0.2 & 0.6 & 0.2 \\
\hline S2 & 1.0 & 1.0 & 1.0 & 0.5 & 0.8 & 0.0 & 0.0 & 0.0 & 0.0 & 0.0 & 1.0 & 0.0 & 1.0 & 1.0 & 0.8 & 0.3 & 0.0 & 0.6 & 0.1 & 0.5 & 0.8 & 0.2 & 0.8 & 0.2 \\
\hline S3 & 0.8 & 0.5 & 0.3 & 0.2 & 1.0 & 0.2 & 0.2 & 0.2 & 0.2 & ק & 0.4 & 05 & 0.0 & 0.5 & 0.8 & 0.2 & 0.5 & 0.2 & 0.2 & 0.2 & 0.9 & 0.1 & 0.1 & 0.3 \\
\hline S4 & 1.0 & 1.0 & 1.0 & 0.0 & 1. & 0.1 & 0. & 0.1 & 0. & 0.1 & 0.0 & 0 & 0.8 & 0.0 & 1.0 & 0.0 & 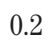 & 0.0 & 0.0 & 1.0 & 0.0 & 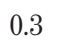 & - & 0.2 \\
\hline S5 & 0.5 & 0.1 & 0.0 & 0.0 & 1. & 0.0 & 0.0 & 0.0 & 0.0 & 0.0 & 0.0 & 0.5 & 0.5 & 1.0 & 0.0 & 0.0 & 1.0 & 1.0 & 0.0 & 0.0 & 0.5 & .2 & 0.1 & 0.2 \\
\hline S6 & 0.0 & 0.8 & 0.0 & 0.0 & 0.8 & 0.0 & 0.0 & 0.0 & 0.0 & 0.0 & 1.0 & 0.5 & 0.5 & 0.3 & 0.0 & 0.0 & 0.0 & 0.0 & 0.0 & 0.5 & 0.0 & 0.3 & 0.8 & 0.0 \\
\hline S7 & 0.0 & 0.0 & 0.0 & 0.0 & 0.5 & 0.0 & 0.0 & 0.0 & 0.0 & 00 & 0.5 & 05 & 0.3 & 03 & 0.1 & 0.0 & 0.0 & 0.2 & 0.5 & 0.5 & 0.5 & 0.2 & 0.0 & 0.0 \\
\hline $\mathrm{T} 1$ & 1.4 & 2.0 & 2.0 & 0.5 & 1.2 & 0.5 & 0.5 & 0.0 & 0.5 & 0.5 & 0. & 0.8 & 0.8 & 0.0 & 0.0 & 0. & 0.0 & 0. & 0. & 2.0 & 1. & 0.5 & .8 & 3 \\
\hline $\mathrm{T} 2$ & 1.0 & 1.0 & 1.2 & 0.0 & 1. & 0.3 & 0. & 0.3 & 0. & 0.3 & 0.8 & 0.4 & 0.5 & 0.3 & 0.0 & 0.0 & 0.5 & 0.0 & 0.0 & 0.0 & 0.0 & 0.5 & 0.8 & 0.2 \\
\hline T3 & 1.5 & 2.0 & 1.5 & 0.0 & 1.0 & 0.0 & 0.0 & 0.0 & 0.0 & 0.0 & 0.5 & 0.3 & 0.3 & 0.1 & 0.0 & 0.0 & 0.2 & 2.0 & 0.3 & 0.0 & 1.0 & 0.5 & 1.0 & 0.4 \\
\hline $\mathrm{T} 4$ & 0.5 & 0.9 & 0.9 & 0.0 & 0.9 & 0.2 & 0.2 & 0.2 & 0.2 & 0.2 & 0.8 & 0.5 & 0.5 & 0.8 & 0.5 & 0.2 & 0.4 & 1.0 & 0.0 & 1.0 & 0.0 & 0.3 & 0.6 & 0.3 \\
\hline $\mathrm{T}$ & 0.2 & 0.5 & 0.4 & 0.0 & 0 . & 0.1 & 0.1 & 0.1 & 0.1 & 0.1 & 0.5 & 1 & 0.2 & 0.4 & 0.2 & 0.0 & 0.0 & 0.2 & 0.0 & 0.6 & 0.5 & 0.0 & 0.5 & 0.1 \\
\hline $\mathrm{T} 6$ & 0.1 & 0.5 & 0.1 & 0.0 & 0.0 & 0.0 & 0.0 & 0.0 & 0.0 & 0.0 & 0.5 & 0.2 & 0.1 & 0.1 & 0.0 & 0.5 & 0.0 & 0.0 & 0.0 & 0.0 & 0.5 & 0.0 & 0.0 & 0.0 \\
\hline $\mathrm{T} 7$ & 0.5 & 0.2 & 0.3 & 0.3 & 0.0 & 0.0 & 0.0 & 0.0 & 0.0 & 0.0 & 0.4 & 0.4 & 0.4 & 0.5 & 0.4 & 0.0 & 0.1 & 0.8 & 0.6 & 0.6 & 0.5 & 0.2 & 0.3 & 0.0 \\
\hline
\end{tabular}

It can be seen that for Business criteria (B) and Technological criteria (T) "Relation" (R-C) is positive and "Prominence" $(\mathrm{R}+\mathrm{C})$ is large. This indicates that these criteria are the key factor for the choice of the transport technology for the carriage of passengers. The Environmental criteria (E) and Social criteria (S) have negative (R-C) and large $(\mathrm{R}+\mathrm{C})$. This shows that they have indirect impact on the studied system.

The DEMATEL method has been applied also for all 24 sub-criteria to investigate their relationships. The study was conducted together for all the sub-criteria. Table 4 shows the average answer matrix for sub-criteria. 
Table 5 Sub-criteria. Total Relation Matrix T and the direct and indirect influence

\begin{tabular}{|c|c|c|c|c|c|c|c|c|c|c|c|c|c|c|c|c|c|}
\hline & B1 & B2 & B3 & B4 & B5 & E1 & $\mathrm{E} 2$ & E3 & $\mathrm{E} 4$ & E5 & S1 & S2 & S3 & $\mathrm{S} 4$ & S5 & S6 & S7 \\
\hline $\mathrm{B} 1$ & $0.08^{*}$ & $0.17^{*}$ & $0.17^{*}$ & $0.07^{*}$ & $0.12 *$ & $0.06^{*}$ & $0.06^{*}$ & $0.06^{*}$ & $0.06^{*}$ & $0.06^{*}$ & $0.12^{*}$ & $0.07 *$ & $0.08^{*}$ & $0.07^{*}$ & $0.07^{*}$ & $0.06^{*}$ & $0.08^{*}$ \\
\hline B2 & $0.15^{*}$ & $0.10^{*}$ & $0.14^{*}$ & $0.10^{*}$ & $0.10^{*}$ & 0.03 & 0.03 & 0.03 & 0.03 & 0.03 & $0.14^{*}$ & $0.07^{*}$ & $0.08^{*}$ & $0.07^{*}$ & $0.06^{*}$ & $0.07^{*}$ & 0.03 \\
\hline B3 & $0.11^{*}$ & $0.18^{*}$ & $0.06^{*}$ & 0.03 & $0.05^{*}$ & 0.02 & 0.02 & 0.02 & 0.02 & 0.02 & $0.07^{*}$ & $0.04^{*}$ & $0.04^{*}$ & 0.03 & 0.02 & $0.04^{*}$ & 0.02 \\
\hline B4 & 0.03 & $0.08^{*}$ & $0.08^{*}$ & 0.01 & 0.02 & 0.03 & 0.03 & 0.03 & 0.03 & 0.03 & 0.02 & 0.03 & 0.01 & 0.01 & 0.01 & 0.01 & 0.01 \\
\hline B5 & $0.08^{*}$ & $0.09 *$ & $0.07^{*}$ & $0.04 *$ & $0.04^{*}$ & 0.03 & 0.03 & 0.03 & 0.03 & 0.03 & $0.08^{*}$ & $0.05^{*}$ & $0.06^{*}$ & $0.07^{*}$ & $0.04^{*}$ & $0.04^{*}$ & 0.03 \\
\hline E1 & $0.06^{*}$ & $0.04^{*}$ & $0.04^{*}$ & 0.01 & $0.04^{*}$ & 0.01 & 0.01 & 0.01 & 0.01 & 0.01 & 0.03 & 0.02 & 0.03 & 0.03 & 0.01 & 0.01 & 0.01 \\
\hline E2 & $0.06^{*}$ & $0.04^{*}$ & $0.04^{*}$ & 0.01 & $0.04^{*}$ & 0.01 & 0.01 & 0.01 & 0.01 & 0.01 & 0.03 & 0.02 & 0.03 & 0.03 & 0.01 & 0.01 & 0.01 \\
\hline E3 & $0.06^{*}$ & $0.04^{*}$ & $0.04^{*}$ & 0.01 & $0.04^{*}$ & 0.01 & 0.01 & 0.01 & 0.01 & 0.01 & 0.03 & 0.02 & 0.03 & 0.03 & 0.01 & 0.01 & 0.01 \\
\hline $\mathrm{E} 4$ & $0.06^{*}$ & $0.04^{*}$ & $0.04^{*}$ & 0.01 & $0.04^{*}$ & 0.01 & 0.01 & 0.01 & 0.01 & 0.01 & 0.03 & 0.02 & 0.03 & 0.03 & 0.01 & 0.01 & 0.01 \\
\hline E5 & $0.06^{*}$ & $0.04^{*}$ & $0.04^{*}$ & 0.01 & $0.04^{*}$ & 0.01 & 0.01 & 0.01 & 0.01 & 0.01 & 0.03 & 0.02 & 0.03 & 0.03 & 0.01 & 0.01 & 0.01 \\
\hline $\mathrm{S} 1$ & $0.08^{*}$ & $0.09 *$ & $0.08^{*}$ & 0.02 & $0.08^{*}$ & 0.02 & 0.02 & 0.02 & 0.02 & 0.02 & $0.04^{*}$ & $0.06^{*}$ & $0.08^{*}$ & $0.07^{*}$ & $0.05^{*}$ & $0.06^{*}$ & $0.06^{*}$ \\
\hline $\mathrm{S} 2$ & $0.12^{*}$ & $0.13^{*}$ & $0.12^{*}$ & $0.05^{*}$ & $0.10^{*}$ & 0.02 & 0.02 & 0.02 & 0.02 & 0.02 & $0.10 *$ & $0.04^{*}$ & $0.09 *$ & $0.09 *$ & $0.07^{*}$ & $0.04^{*}$ & 0.02 \\
\hline S3 & $0.09 *$ & $0.08^{*}$ & $0.06^{*}$ & 0.03 & & 0.02 & & & 0.02 & & & $0.05^{*}$ & 0.03 & $0.06^{*}$ & $0.07^{*}$ & 0.03 & $0.05^{*}$ \\
\hline $\mathrm{S} 4$ & $0.12^{*}$ & $0.13^{*}$ & $0.12^{*}$ & 0.02 & $0.11^{*}$ & 0.02 & 0.02 & 0.02 & 0.02 & 0.02 & $0.08^{*}$ & $0.08^{*}$ & $0.08^{*}$ & $0.04^{*}$ & $0.08^{*}$ & 0.02 & 0.03 \\
\hline S5 & $0.06^{*}$ & $0.05^{*}$ & $0.04^{*}$ & 0.01 & $0.09 *$ & 0.01 & 0.01 & 0.01 & 0.01 & 0.01 & $0.03^{*}$ & $0.05^{*}$ & $0.05^{*}$ & $0.08^{*}$ & 0.02 & 0.01 & $0.07^{*}$ \\
\hline S6 & 0.03 & $0.08^{*}$ & 0.03 & 0.01 & $0.07^{*}$ & 0.01 & 0.01 & 0.01 & 0.01 & 0.01 & $0.08^{*}$ & $0.04^{*}$ & $0.05^{*}$ & 0.03 & 0.01 & 0.01 & 0.01 \\
\hline $\mathrm{S} 7$ & 0.02 & 0.03 & 0.02 & 0.01 & $0.05^{*}$ & 0.01 & 0.01 & 0.01 & 0.01 & 0.01 & $0.05^{*}$ & $0.04^{*}$ & 0.03 & 0.03 & 0.02 & 0.01 & 0.01 \\
\hline $\mathrm{T} 1$ & $0.17^{*}$ & $0.22^{*}$ & $0.20^{*}$ & $0.06^{*}$ & $0.13^{*}$ & $0.05^{*}$ & $0.05^{*}$ & $0.05^{*}$ & $0.05^{*}$ & $0.05^{*}$ & $0.07^{*}$ & $0.09 *$ & $0.09 *$ & $0.04^{*}$ & 0.03 & 0.03 & 0.03 \\
\hline $\mathrm{T} 2$ & $0.10^{*}$ & $0.11^{*}$ & $0.11^{*}$ & 0.02 & $0.09^{*}$ & 0.03 & 0.03 & 0.03 & 0.03 & 0.03 & $0.08^{*}$ & $0.05^{*}$ & $0.06^{*}$ & $0.04^{*}$ & 0.02 & 0.02 & 0.04 \\
\hline $\mathrm{T} 3$ & $0.16^{*}$ & $0.21^{*}$ & $0.16^{*}$ & 0.03 & $0.12^{*}$ & 0.02 & 0.02 & 0.02 & 0.02 & 0.02 & $0.09 *$ & $0.06^{*}$ & $0.06^{*}$ & $0.04^{*}$ & 0.03 & 0.03 & 0.03 \\
\hline $\mathrm{T} 4$ & $0.09^{*}$ & $0.12^{*}$ & $0.11^{*}$ & 0.02 & $0.10^{*}$ & 0.03 & 0.03 & 0.03 & 0.03 & 0.03 & $0.09 *$ & $0.06^{*}$ & $0.06^{*}$ & $0.08^{*}$ & $0.05^{*}$ & 0.03 & $0.04^{*}$ \\
\hline T5 & $0.04^{*}$ & $0.06^{*}$ & $0.05^{*}$ & 0.01 & $0.05^{*}$ & 0.01 & 0.01 & 0.01 & 0.01 & 0.01 & $0.05^{*}$ & 0.02 & 0.03 & $0.04^{*}$ & 0.02 & 0.01 & 0.01 \\
\hline $\mathrm{T} 6$ & 0.02 & $0.04^{*}$ & 0.02 & 0.01 & 0.01 & 0.00 & 0.00 & 0.00 & 0.00 & 0.00 & $0.04^{*}$ & 0.02 & 0.02 & 0.01 & 0.01 & 0.03 & 0.01 \\
\hline $\mathrm{T} 7$ & $0.07^{*}$ & $0.06^{*}$ & $0.06^{*}$ & 0.03 & 0.03 & 0.01 & 0.01 & 0.01 & 0.01 & 0.01 & $0.05^{*}$ & $0.04 *$ & $0.05^{*}$ & $0.05^{*}$ & $0.04^{*}$ & 0.01 & 0.02 \\
\hline
\end{tabular}

Table 6 Sub - criteria. Total Relation Matrix T and the direct and indirect influence

\begin{tabular}{|c|c|c|c|c|c|c|c|c|c|c|c|c|}
\hline & $\mathrm{T} 1$ & $\mathrm{~T} 2$ & T3 & $\mathrm{T} 4$ & $\mathrm{~T} 5$ & $\mathrm{~T} 6$ & $\mathrm{~T} 7$ & $\mathrm{R}+\mathrm{C}$ & $\mathrm{R}-\mathrm{C}$ & e (\%) & Rank & Impact \\
\hline B1 & $0.09^{*}$ & $0.05^{*}$ & $0.09 *$ & $0.09^{*}$ & $0.05^{*}$ & $0.11^{*}$ & $0.04 *$ & 3.91 & 0.09 & 7.83 & 2 & Cause \\
\hline B2 & $0.14^{*}$ & $0.08^{*}$ & $0.15^{*}$ & $0.08^{*}$ & $0.05^{*}$ & $0.11^{*}$ & 0.03 & 4.13 & -0.32 & 8.29 & 1 & Effect \\
\hline B3 & $0.13^{*}$ & $0.03^{*}$ & $0.11^{*}$ & $0.07^{*}$ & 0.03 & $0.06^{*}$ & 0.02 & 3.14 & -0.64 & 6.30 & 5 & Effect \\
\hline B4 & 0.02 & 0.01 & 0.02 & 0.02 & 0.01 & 0.03 & 0.02 & 1.22 & 0.00 & 2.44 & 18 & Cause \\
\hline B5 & $0.06^{*}$ & $0.04^{*}$ & $0.07^{*}$ & $0.08^{*}$ & $0.04^{*}$ & $0.06^{*}$ & 0.01 & 2.90 & -0.44 & 5.81 & 6 & Effect \\
\hline E1 & 0.02 & 0.01 & 0.02 & 0.03 & 0.01 & 0.01 & 0.01 & 0.94 & -0.03 & 1.89 & 20 & Effect \\
\hline E2 & 0.02 & 0.01 & 0.02 & 0.03 & 0.01 & 0.01 & 0.01 & 0.94 & -0.03 & 1.89 & 21 & Effect \\
\hline E3 & 0.02 & 0.01 & 0.02 & 0.03 & 0.01 & 0.01 & 0.01 & 0.94 & -0.03 & 1.89 & 22 & Effect \\
\hline $\mathrm{E} 4$ & 0.02 & 0.01 & 0.02 & 0.03 & 0.01 & 0.01 & 0.01 & 0.94 & -0.03 & 1.89 & 23 & Effect \\
\hline E5 & 0.02 & 0.01 & 0.02 & 0.03 & 0.01 & 0.01 & 0.01 & 0.94 & -0.03 & 1.89 & 24 & Effect \\
\hline $\mathrm{S} 1$ & $0.05^{*}$ & $0.04^{*}$ & $0.07^{*}$ & 0.08 & 0.03 & $0.07^{*}$ & 0.02 & 2.72 & -0.26 & 5.46 & 8 & Effect \\
\hline $\mathrm{S} 2$ & $0.09 *$ & 0.03 & $0.08^{*}$ & $0.09^{*}$ & 0.03 & $0.09^{*}$ & 0.03 & 2.55 & 0.46 & 5.11 & 10 & Cause \\
\hline S3 & $0.05^{*}$ & 0.03 & $0.05^{*}$ & $0.08^{*}$ & 0.02 & $0.04^{*}$ & 0.03 & 2.27 & -0.10 & 4.54 & 11 & Effect \\
\hline $\mathrm{S} 4$ & $0.10^{*}$ & 0.02 & $0.11^{*}$ & $0.08^{*}$ & $0.04^{*}$ & $0.07^{*}$ & 0.03 & 2.56 & 0.38 & 5.13 & 9 & Cause \\
\hline S5 & $0.08^{*}$ & 0.01 & 0.03 & $0.06^{*}$ & 0.03 & 0.03 & 0.02 & 1.66 & 0.08 & 3.33 & 13 & Cause \\
\hline S6 & 0.02 & 0.01 & $0.05^{*}$ & 0.02 & 0.03 & $0.07^{*}$ & 0.01 & 1.30 & 0.10 & 2.60 & 17 & Cause \\
\hline S7 & 0.03 & $0.04^{*}$ & $0.05^{*}$ & $0.05^{*}$ & 0.02 & 0.02 & 0.01 & 1.19 & -0.10 & 2.38 & 19 & Effect \\
\hline $\mathrm{T} 1$ & $0.08 *$ & 0.03 & $0.18^{*}$ & $0.12^{*}$ & $0.06^{*}$ & $0.11^{*}$ & $0.04^{*}$ & 3.49 & 0.55 & 6.99 & 3 & Cause \\
\hline $\mathrm{T} 2$ & $0.04 *$ & 0.02 & $0.04^{*}$ & 0.04 & $0.04^{*}$ & $0.08^{*}$ & 0.02 & 1.77 & 0.56 & 3.55 & 12 & Cause \\
\hline $\mathrm{T} 3$ & $0.18^{*}$ & $0.04^{*}$ & $0.07 *$ & $0.11^{*}$ & $0.06^{*}$ & $0.11^{*}$ & $0.04^{*}$ & 3.23 & 0.28 & 6.47 & 4 & Cause \\
\hline $\mathrm{T} 4$ & $0.11^{*}$ & 0.02 & $0.11^{*}$ & $0.05^{*}$ & $0.04^{*}$ & $0.08^{*}$ & 0.03 & 2.83 & 0.02 & 5.67 & 7 & Cause \\
\hline T5 & $0.04^{*}$ & 0.01 & $0.06^{*}$ & $0.05^{*}$ & 0.01 & $0.05^{*}$ & 0.01 & 1.35 & 0.03 & 2.71 & 15 & Cause \\
\hline T6 & 0.01 & 0.01 & 0.01 & $0.04^{*}$ & 0.01 & 0.01 & 0.00 & 1.65 & -0.96 & 3.31 & 14 & Effect \\
\hline $\mathrm{T} 7$ & $0.08^{*}$ & $0.04^{*}$ & $0.06^{*}$ & $0.06^{*}$ & 0.03 & $0.04^{*}$ & 0.01 & 1.30 & 0.44 & 2.61 & 16 & Cause \\
\hline
\end{tabular}




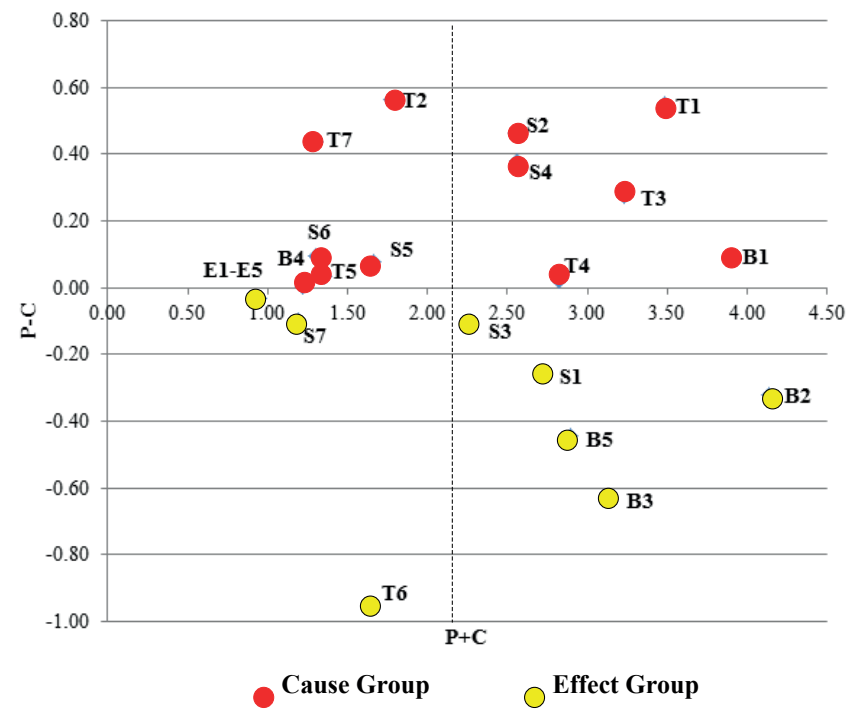

Figure 2 The cause and effect diagram of all the sub-criteria

Table 5 and Table 6 present Total Relation Matrix T and the direct and indirect influence. The threshold value determined by Equation (7) is 0.044 . The elements that are larger than the threshold value are marked. The end column of the Table 6 indicates the weights of criteria. The results in Table 5 and Table 6 show:

- The Ticket price (B2) has the highest degree of importance (weight 8.29\%).

- The prioritization is: $\mathrm{B} 2>\mathrm{B} 1>\mathrm{T} 1>\mathrm{T} 3>\mathrm{B} 3>\mathrm{B} 5>\mathrm{T} 4>\mathrm{S} 1>$ $\mathrm{S} 4>\mathrm{S} 2>\mathrm{S} 3>\mathrm{T} 2>\mathrm{S} 5>\mathrm{T} 6>\mathrm{T} 5>\mathrm{T} 7>\mathrm{S} 6>\mathrm{B} 4>\mathrm{S} 7>\mathrm{E} 1>\mathrm{E} 2>\mathrm{E} 4$ $>\mathrm{E} 5>\mathrm{E} 3$.

- The sub-criteria Ticket price (B2) and Costs for fuel (B1) have close weights.

The sub-criteria in cause group that have positive (P-C) are: Costs for fuel (B1), Security (S2), Stability (S4), Punctuality (S5), Cleanliness, ergonomics (S6), Time travel (T1), Frequency of shipments (T2); Directness (T3); Number of stops (T4), Service period (T5) and State of infrastructure (T7). Therefore, they are in the cause group. The sub-criteria Ticket price (B2), Direct operating costs (B3), Company position in the market (B5), Ecological subcriteria E1-E5, Comfort (S1), - Reliability (S3), Security and comfort in the place of time-off (S7), Vehicle occupancy rate (T6) have negative values of the (R-C). Therefore, they are in the effect group.

Results in Table 6 also show ranking of the sub-criteria. The sub-criteria of the main group Business (B) and Technological $(\mathrm{T})$ are ranked in the first seven positions $\mathrm{B} 2>\mathrm{B} 1>\mathrm{T} 1>\mathrm{T} 3>\mathrm{B} 3>\mathrm{B} 5>\mathrm{T} 4$. These results are similar to ranking of the main group criteria, where Business (B) and technological (T) criteria are ranked first and second.

Figure 2 presents the cause and effect diagram of all sub-criteria. The parts of the diagram are formed according to the main of $(\mathrm{R}+\mathrm{C})$; it is 2.065 (by Table 6 , value is 4.13 ). The dashed line in the figure shows the division of the four parts.

The sub-criteria located above the abscissa are in the cause group; the sub-criteria located below the abscissa are in the effect group. The sub-criteria Transport costs for fuel (B1), Security (S2), Stability (S4), Time travel (T1), Directness (T3) and Number of stops (T4) are in the part of the diagram where the "Relation" (R-C) is positive and "Prominence" $(\mathrm{R}+\mathrm{C})$ is large. This indicates that these criteria are the key factor for the choice of transport technology for the carriage of passengers. The sub-criteria Comfort (S1), Reliability (S3), Ticket price (B2), Direct operating costs (B3) and Company position in the market (B5) have a negative $(\mathrm{R}-\mathrm{C})$ and large $(\mathrm{R}+\mathrm{C})$. This shows that they have indirect impact on the studied system.

The sub-criteria Infrastructure charges (B4), Punctuality (S5), Cleanliness, ergonomics (S6), Frequency (T2), Service period (T5) and State of infrastructure (T7) have positive $(\mathrm{R}-\mathrm{C})$ and small $(\mathrm{R}+\mathrm{C})$, which indicates that these criteria are independent and influenced only by a few other factors. The sub-criteria E1-E5, Security and comfort in the place of time-off (S7) and Vehicle occupancy rate (T6) negative (R-C) and small $(\mathrm{R}+\mathrm{C})$, which shows that they are independent and can be influenced by a few other factors.

Figure 3, Figure 4, Figure 5 and Figure 6 present examples of the cause and effect diagram for some of criteria. Figures are compiled according to results in marked values given in Table 5 and Table 6 . Arrows in figures present the relationships between criteria according to the threshold value and the marked elements in the total relation matrix presented in Table 5 and Table 6 . Figure 3 shows the relationship for the sub-criterion Ticket price (B2). This sub-criterion is in the Effect group.

The strongest relationships for the ticket price (B2) are with Costs for fuel (B1), Direct operating costs (B3), Comfort (S1), Time travel (T1) and Directness (T3) (values of Total Relation Matrix between 0.14-0.15). Figure 4 shows the relationship for sub-criterion Time travel (T1). This subcriterion is in the cause group. The strongest relationships for Time travel (T1) are with Ticket price (B2), Direct operating costs (B3) and Directness (T3) (values of Total Relation Matrix between $0.20-0.22$ ). Figure 5 presents relationship for the ecological sub-criteria E1-E5. These 


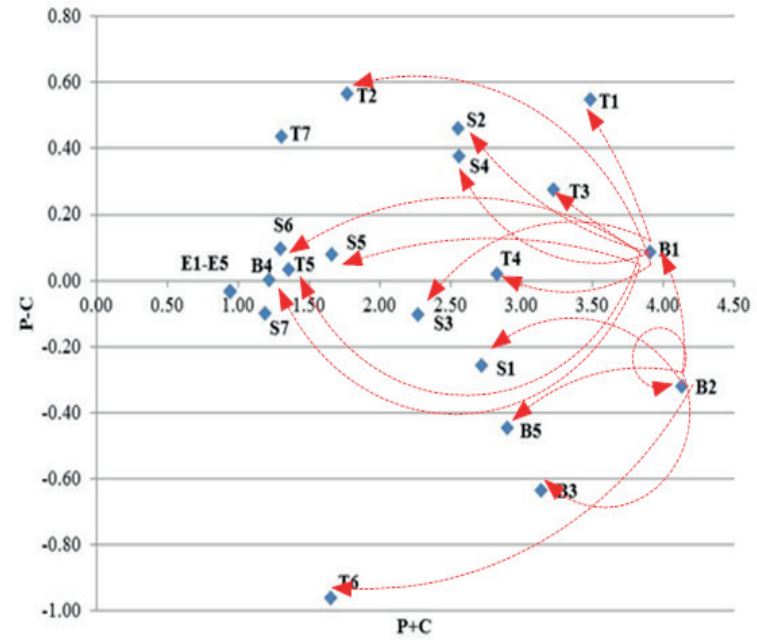

Figure 3 The cause and effect diagram for the sub-criterion B2. Threshold value $v=0.04$

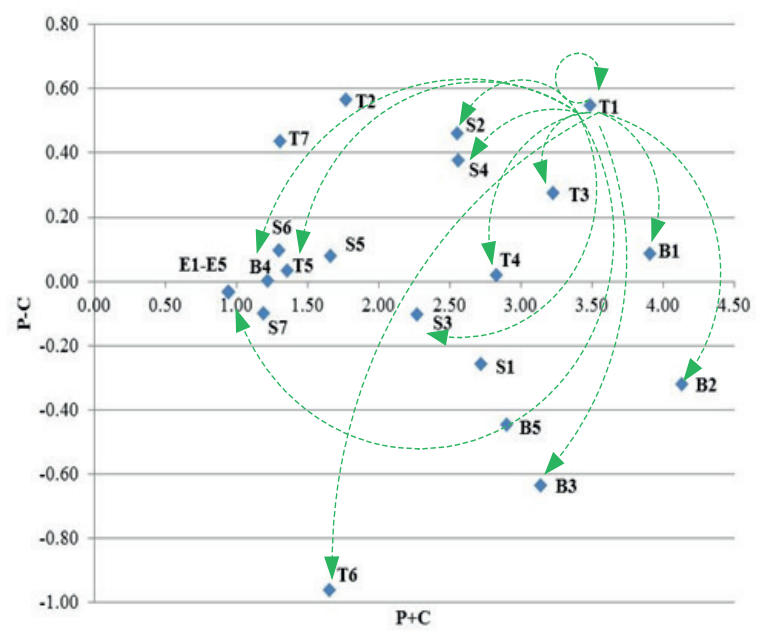

Figure 4 The cause and effect diagram for the sub-criterion T1. Threshold value $v=0.04$

sub-criteria are in effect group. The strongest relationships these sub-criteria have with costs for fuel (B1), (values of Total Relation Matrix between $0.20-0.22$ ). Figure 6 shows the relationship for sub-criterion Security (S2). This subcriterion is in cause group. The strongest relationships for Security (S2) are with Costs for fuel (B1), Ticket price (B2), Direct operating costs (B3) (values of Total Relation Matrix between 0.12-0.13).

\section{Conclusions}

This research defined the criteria for the choice of transport technology for the carriage of passengers. The DEMATEL multi-criteria method has been applied to study the impact and the influence of the criteria on one another. Four main criteria and 24 sub-criteria have been defined. It was found that the Business criteria have the highest degree of importance (29.47\%). The Business criteria and Technological criteria are in the cause group. The Environmental criteria and Social criteria have

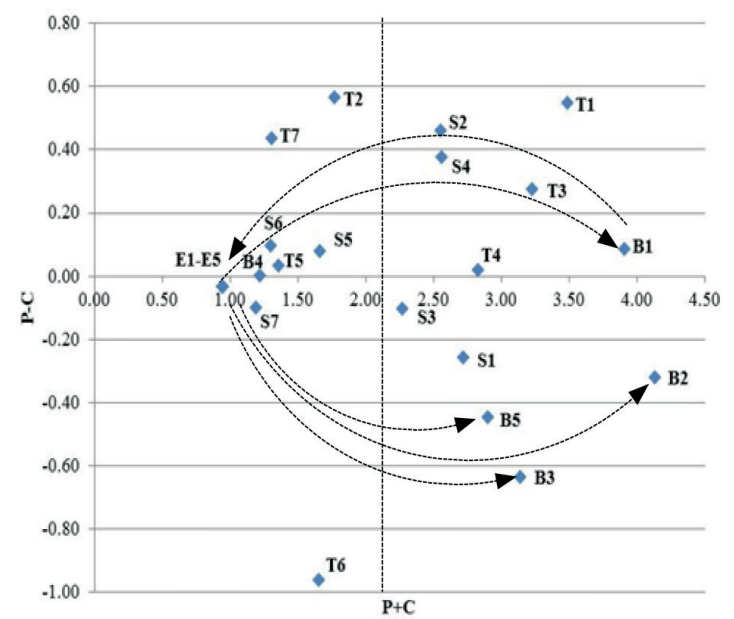

Figure 5 The cause and effect diagram for the sub-criteria E1-E5. Threshold value $v=0.04$

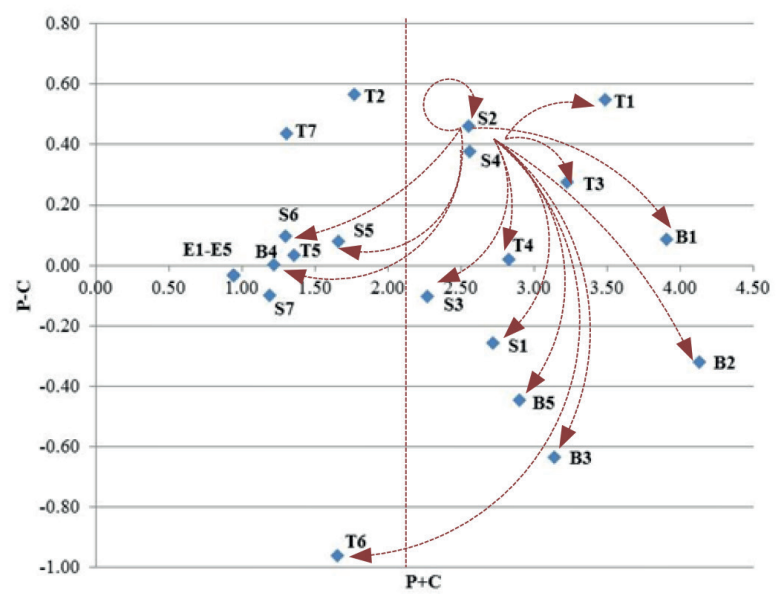

Figure 6 The cause and effect diagram for the sub-criterion S2. Threshold value $v=0.04$

indirect impact on the studied system. The criteria of great importance are the transport costs for fuel (7.83\%); ticket price (8.29\%); time travel (6.99\%); directness (6.47\%) and direct operating costs (6.30\%).

The sub-criteria Transport costs for fuel (B1), Security (S2), Stability (S4), Time travel (T1), Directness (T3) and Number of stops (T4) are the key factor for the choice of transport technology for the carriage of passengers. The sub-criteria Comfort (S1), Reliability (S3), Ticket price (B2), Direct operating costs (B3) and Company position in the market (B5) have indirect impact on the studied system. The sub-criteria of the main group Business (B) and Technological (T) are ranked at the first seven positions. These results are similar to the ranking of the main group criteria, where Business (B) and technological (T) criteria are ranked as the first and second.

The defined criteria and the received results can be applied for evaluation, comparison and selection of variants of carriage with different modes of transport. Results for the criteria weights can be used as input data when applying another method of ranking the transportation alternative. 


\section{Acknowledgments}

This research has been supported by contract NoKP06-H27/12 of 11.12.2018 "Modelling and elaboration of complex system for selection of transport technology in transport network" funded by the National Science Fund of the Ministry of Education and Science of Bulgaria.

\section{References}

[1] GUNER, S. Measuring the quality of public transportation systems and ranking the bus transit routes using multicriteria decision making techniques. Case Studies on Transport Policy [online]. 2018, 6(2), p. 214-224 [accessed 202003-15]. ISSN 2213-624X. Available from: https://doi.org/10.1016/j.cstp.2018.05.005

[2] DEVECI, M., ONER, S. G., CANITEZ, F., ONER, M. Evaluation of service quality in public bus transportation using intervalvalued intuitionistic fuzzy QFD methodology. Research in Transportation Business and Management [online]. 2019, 100387 [accessed 2020-03-15]. ISSN 2210-5395. Available from: https://doi.org/10.1016/j.rtbm.2019.100387

[3] BURGDORF, C., EISENKOPF, A., KNORR, A. User acceptance of long distance bus services in Germany. Research in Transportation Economics [online]. 2018, 69, p. 270-283 [accessed 2020-03-15]. ISSN 0739-8859. Available from: https://doi.org/10.1016/j.retrec.2018.07.023

[4] CYRIL, A., RAVIRAJ, H. M., VARGHESE, G. Performance optimization of public transport using integrated AHP-GP methodology. Urban Rail Transit [online]. 2019, 5(2), p. 133-144 [accessed 2020-03-15]. ISSN 2199-6679. Available from: https://doi.org/10.1007/s40864-019-0103-2

[5] OLIVKOVA, I. Evaluation of quality public transport criteria in terms of passenger satisfaction Transport and Telecommunication [online]. 2016, 17(1), p. 18-27 [accessed 2020-03-15]. ISSN 1407-6160. Available from: https://doi.org/10.1515/ttj-2016-0003

[6] SHEN, X., FENG, S., LI, Z., HU, B. Analysis of bus passenger comfort perception based on passenger load factor and in vehicle time. SpringerPlus [online]. 2016, 5(62). ISSN 2193-1801 [accessed 2020-03-15]. Available from: https://doi.org/10.1186/s40064-016-1694-7

[7] FREITAS, A. L. P. Assessing the quality of intercity road transportation of passengers: an exploratory study in Brazil. Transportation Research Part A [online]. 2013, 49, p. 379-392 [accessed 2020-03-15]. ISSN 0965-8564. Available from: https://doi.org/10.1016/j.tra.2013.01.042

[8] MAVIR, K., ZARBAKHSHNIA, N., KHAZRAEI, A. Bus rapid transit (BRT): a simulation and multi criteria decision making (MCDM) approach. Transport Policy [online]. 2018, 72, p. 187-197 [accessed 2020-03-15]. ISSN 0967-070X. Available from: https://doi.org/10.1016/j.tranpol.2018.03.010

[9] JAVID, R. J., NEJAT, A., HAYHOE, K. Selection of CO2 mitigation strategies for road transportation in the United States using a multi-criteria approach. Renewable and Sustainable Energy Reviews [online]. 2014, 38, p. 960-972 [accessed 2020-03-15]. ISSN 1364-0321. Available from: https://doi.org/10.1016/j.rser.2014.07.005

[10] ZAK, J., FIEREK, S., KRUSZYNSKI, M. Evaluation of different transportation solutions with the application of macro simulation tools and multiple criteria group decision making / aiding methodology. Procedia - Social and Behavioral Sciences [online]. 2014, 111, p. 340-349 [accessed 2020-03-15]. ISSN 1877-0428. Available from: https://doi.org/10.1016/j. sbspro.2014.01.067

[11] BARANA, J., ZAK, J. Multiple criteria evaluation of transportation performance for selected agribusiness companies. Procedia - Social and Behavioral Sciences [online]. 2014, 111, p. 320-329 [accessed 2020-03-15]. ISSN 1877-0428. Available from: https://doi.org/10.1016/j.sbspro.2014.01.065

[12] ISAAI, M., KANANI, A., TOOTOONCHI, M., AFZALI, H. Intelligent timetable evaluation using fuzzy AHP. Expert Systems with Applications [online]. 2011, 38, p. 3718-3723 [accessed 2020-03-15]. ISSN 0957-4174. Available from: https://doi.org/10.1016/j.eswa.2010.09.030

[13] WEN, H., LIN, S., Performance evaluation of highway passenger transport enterprises' operation based on the model of AHP-DEA. In: IEEE 18th International Conference on Industrial Engineering and Engineering Management: proceedings [online]. Vol. 2. IEEE, 2011 [accessed 2020-03-15]. ISSN 00002011, p. 811-815. Available from: https://doi.org/10.1109/ICIEEM.2011.6035283

[14] STOILOVA, S. An integrated approach for transport scheme selection of intercity trains on railway networks. Promet - Traffic - Traffico [online]. 2019, 30(4), p. 367-377 [accessed 2020-03-15]. ISSN 1848-4069. Available from: https://doi.org/10.7307/ptt.v30i4.2673

[15] STOILOVA, S. A multi-criteria selection of the transport plan of intercity passenger trains. IOP Conference Series: Materials Science and Engineering [online]. 2019, 664(1), 012031 [accessed 2020-03-15]. ISSN 1757-899X. Available from: https://doi.org/10.1088/1757-899X/664/1/012031 
[16] BUDHIARTINI, D., ISNAINI, J. Consumer perspective on public transport: the medan-pematang siantar route as a case study. Communications - Scientific letters of the University of Zilina [online]. 2020, 22(1), p. 3-8 [accessed 2020-0315]. ISSN 1335-4205, eISSN 2585-7878. Available from: https://komunikacie.uniza.sk/index.php/communications/article/ view/1526

[17] VUJANOVIC, D., MOMCILOVIC, V., BOJOVIC, N., PAPIC, V. Evaluation of vehicle fleet maintenance management indicators by application of DEMATEL and ANP. Expert Systems with Applications [online]. 2012, 39, p. 10552-10563 [accessed 2020-03-15]. ISSN 0957-4174. Available from: https://doi.org/10.1016/j.eswa.2012.02.159

[18] HSIEH YF., LEE YC., LIN SB. Rebuilding DEMATEL threshold value: an example of a food and beverage information Springer Plus [online]. 2016, 5(1), 1385. ISSN 2193-1801 [accessed 2020-03-15]. Available from: https://doi.org/10.1186/ s40064-016-3083-7

[19] HWANG, W., HSIAO, B., CHEN, H-G.CHERN, C-C. Multiphase assessment of project risk interdependencies: evidence from a University ISD project in Taiwan. Project Management Jourmal [online]. 2016, 47(1), p. 59-75 [accessed 2020-03-15]. ISSN 1938-9507. Available from: https://doi.org/10.1002/pmj.21563 